\title{
Numerical study of water plume behavior under shallow depth explosion
}

\author{
C.-C. Liang, T.-H. Liu \& W.-M. Tseng \\ Department of Mechanical and Automation Engineering, \\ Da-Yeh University, Taiwan, ROC
}

\begin{abstract}
The most obvious and spectacular features of underwater explosions are the disturbances of the water surface above the charge. The overall hydrodynamic phenomena involved in this process are extremely complicated. Much of the present knowledge and understanding of this field was acquired because of the demands and the few available discussions of the subject have become inadequate or obsolete. This paper evaluates and proceeds on simulation ability of shallow depth explosion plume by MSC.Dytran finite element software. Also in this paper, numerical studies of explosion plume which includes contours of the plume (plume height, plume width and plume thickness) are investigated in details and compared with the relative literature's empirical methodology. The studies presented in this paper attempt to supply a reasonable comprehensive account, which will be used for workers in the field of underwater explosion and others who are interested in the water Barrier Defense.
\end{abstract}

Keywords: underwater explosion, shock bubble, water plume, water barrier.

\section{Introduction}

The phenomena of water plume (Figure 1) during an underwater explosion of solid explosives are still not very well understood. The most obvious features above the surface depend considerably on the initial depth of the charge, being quite spectacular for shallow explosions. The sequence of events in the shallow case may be quite complicated, but three main phases can be distinguished. These results form the arrival of the primary shock wave at the surface, and the final breakthrough of the gases to the atmosphere [1-3]. The first effect of the explosion to arrive at the surface is the underwater shock wave. The shock wave 
arrival at different points is visible as a rapidly expanding ring of apparently darkened water, often called the slick. This ring owes its contrast against the background to the fact that ripples or small waves are calmed by the reflected shock wave pressure and a layer of cavitated, bubbly water is formed. Following the slick is the growth of the spray dome, a whitish mound of broken water thrown up by the reflection of the shock wave at the surface. The extent to which a visible upward motion can be seen around this point is determined by the pressure and the effect of cavitation. The water thrown up near the center of the explosion rises more rapidly, and continues to rise for a longer time than the water further away, and as a result, the dome grows steeper sided as it rises. The time during which the rise continues and the maximum height, reached when the opposing forces of gravity and air resistance have reduced the velocity to zero, depend on the initial pressure and velocity, which in turn depend on the weight of charge and its depth below the surface. For shallow charges, the products of explosion retain their identity in the gas bubble until this bubble reaches the surface and venting occurs. The size and state of motion of the bubble at this time both change greatly with the initial depth, and as a consequence, the effects of venting also vary markedly with depth. The results so far discussed by the literature are evidently rather incomplete from several points of view.

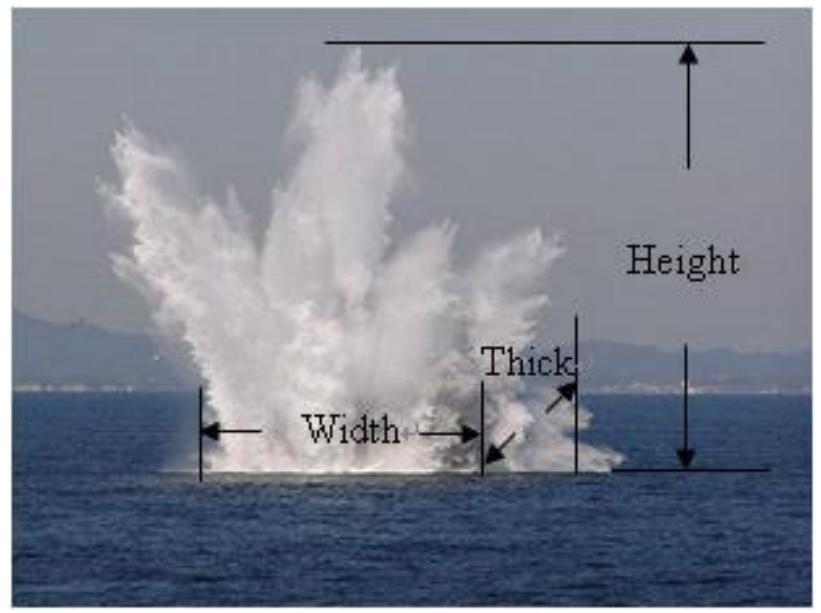

Figure 1: Water plume of an underwater explosion.

A more thorough study should include consideration of dome formation, the internal structure of the dome, and the effect of charge depth. The phenomenon in its entirety is a fairly elaborate one, as yet imperfectly understood. Although some sources of the qualitative introductory discussion based largely on photographic records obtained at Woods Hole, especially the results reported by Cole [1], have been identified in the past. For example, initial formulation of the spray dome, development of the dome, plume formulation, shock wave spread, 
sound ranging and bubble period measurement etc., the water plume process cannot be fully explained by these mechanisms.

In this paper, the formulation of water plume of underwater explosion near air-water surface is quantitatively examined using the finite element method. An Eulerian finite element mesh in which the finite element mesh is stationary and material flows through the mesh was utilized. The finite element program MSC/Dytran (Mac Neal-Schwendler Corporation, 2002) was used in this paper [4]. Also in this paper, numerical studies of explosion plume which includes contours of the plume (plume height, plume width and plume thickness) and duration decreasing for charges fired at different depth are investigated in details and compared with Michael's empirical methodology. The studies presented in this paper attempt to supply a reasonable comprehensive account, which will be used for workers in the field of underwater explosion.

\section{Theoretical background}

The finite element program MSC.Dytran [4] was used for the prediction of water plume behavior of underwater explosion near air-water surface. MSC.Dytran is a three-dimensional analysis code for analyzing the dynamic, nonlinear behavior of fluid, solid components, and structures. It uses explicit time integration and incorporates features that simulate a wide range of material and geometric nonlinearity. It is particularly suitable for analyzing short, transient dynamic events that involve large deformations, a high degree of nonlinearity, and interactions between fluid and structures. Typical applications include: explosives, blasting loading, and underwater shock analysis. Three-dimensional Eulerian elements can be used to create Eulerian meshes and Eulerian solvers can handle hydrodynamic materials. A general material facility can be used to define a wide range of material models including explosive burn models. Loads can be applied to material in the Eulerian mesh by pressure or flow boundaries, and initial conditions of element variables can be prescribed. Rigid walls can be created that act as barriers to prevent the flow of Eulerian material. The theoretical background and numerical approach that govern the evolution of the flow, with the primary aim being a concise description of the basis of the procedure used were to obtain the numerical results of water plumes, shall be summarized in [4].

\section{Michael and Swisdak formulation for water plume of underwater TNT explosion}

Michael and Swisdak's report [5] contains tables, charts, and graphs of effects of explosives detonated underwater. This compilation enables the user to find, in one report, much of the information he required without having to do an extensive literature search. The information of maximum height and radius of the plume from an underwater TNT explosion, either on or off the bottom from Michael and Swisdak's report is adopted to make validation with MSC.Dytran finite element solution. Figure 1 shows a typical plume and defines both 
maximum height and radius. $\mathrm{W}$ is the charge weight in kilograms, and $\mathrm{Y}$ is the charge depth in meters.

The definition of scaled charge depth is:

$$
\text { Scaled charge depth }\left(\mathrm{M} / \mathrm{kg}^{1 / 4}\right)=\mathrm{Y} / \mathrm{W}^{1 / 4} \text {. }
$$

With the value of scaled charge depth, enter the Table of [5] and read corresponding scaled radius $\left(\mathrm{m} / \mathrm{kg}^{1 / 3}\right)$ and scaled height $\left(\mathrm{m} / \mathrm{kg}^{1 / 3}\right)$ with suitable interpolation, then one obtains:

Maximum radius $(\mathrm{m})$ of water plume $=$ Scaled radius $x \mathrm{~W}^{1 / 3}$

Maximum height $(\mathrm{m})$ of water plume $=$ Scaled height $\mathrm{xW}^{1 / 3}$

Michael and Swisdak's report caveat that the curves and tables presented in their report were developed for establishment of safe distances. Actual water plume dimensions may be as much as $50 \%$ less in some cases.

\section{Numerical explosion and validation}

MSC.Dytran is implemented based on the methodologies of Eulerian element, Ignition and Growth (IG) explosive material, approximate Reimann Scheme \& entropy fix etc. to simulate the behavior of water plume of underwater explosion. In order to test the efficiency and ability of MSC.Dytran, extensive numerical tests have been performed. A numerical example is studied in this paper. The water plume is formulated by $9.1 \mathrm{~kg}$ TNT charge fires at $10 \mathrm{~m}$ below the water surface. Because there was no nearby boundary in this numerical test, it approximates the simplest possible case in which the boundaries are located at infinity. This problem was used to examine the underlying physics of shallow underwater explosion. A number of simplifying modeling assumptions were made for this test. The fluid was assumed to be compressible but inviscid and irrotational. Heat transfer between surrounding fluid and the explosion product gases were assumed to be negligible over the time frame of the problem, and as a result vaporization of seawater at the interface between the two was assumed to be insignificant. Mass transfer between the seawater and the explosion product gases, a fraction of which would be water vapor, was also assumed to be negligible.

\subsection{Problem description}

In seawater, the geometric of this essentially free-field problem is illustrated in Figure 2 .

This example studied the water plume formulation by $9.1 \mathrm{~kg}$ TNT changed fired at $10 \mathrm{~m}$ below surface water. In this example, validations of the 2-D computational model are presented. Comparisons of the computations to empirical data include plume height and plume radius are calculated form Michael's and Swisdak's formulations.

\subsection{Model description}

In this simulation, the relative positions of the explosives, water, air and waterair surface are shown in Figure 3. 
The Euler domain and its enclosing surface are shown in Figure 3. The outer boundaries (edge C-D, edge D-E-F, and edge F-D) of Euler domain are given by a sufficient large fixed plume to prevent reflection from the boundaries from affecting the explosion products during the time frame of the analysis. Pressure at the outer boundaries is set to the hydrostatic pressure. This behaves like an open boundary. The Euler mesh contains the water, the air-water surface and the air. The explosive TNT is created in this Euler mesh, too. Figure 4 shows the overall geometry of the finite element model used for this problem and consists of 10000 Eulerian elements and 20402 nodes which contain explosive, water and air. However, if we assume that explosive is a ball, the radius of the ball is only $0.11 \mathrm{~m}$. A fine mesh has to be created to simulate this small ball.

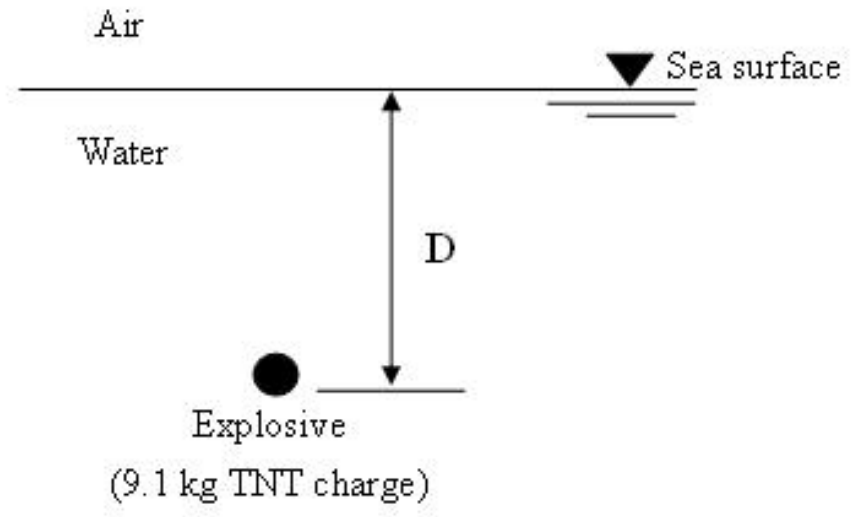

Figure 2: Configuration of $9.1 \mathrm{~kg}$ TNT charge fires at 10 meter below sea surface $(\mathrm{D}=10 \mathrm{~m})$.

\subsection{Results and discussion}

As shown in Figure 5, when we increased the depth of explosion as $10 \mathrm{~m}$, the hydrostatic pressure was bigger than the former one (the depth of explosion was $5 \mathrm{~m}$,) so the velocity of the bubble expanding was slower. During the first bubble expanding, the height of the plume resulted from the bubble pushed the free surface upward was slower than the former one when at $0.2 \sim 1.0 \mathrm{~s}$, respectively. After $1.4 \mathrm{~s}$ of the explosion, the bubble would lose kinetic energy and began to compress due to the surrounded hydrostatic pressure. At this time, the difference of the hydrostatic pressure between the top and the bottom of the bubble was very big. During the compression, the flows of the bottom and both sides of the bubble were faster than the top of the bubble.

Therefore, the central plume kept moving upward and formed an upward jet then became a plume. At $1.8 \mathrm{~s}$, the plume kept rising due to the inertia of the bubble. At $2.2 \sim 3.0 \mathrm{~s}$, the bubble kept compressing; at $3.0 \mathrm{~s}$, the bubble compressed to the minimum volume; when the explosion time reached $3.4 \sim$ $5.0 \mathrm{~s}$, the bubble expanded again and pushed the seawater outward gradually, and the side jet occurred. 
18 Structures Under Shock and Impact IX

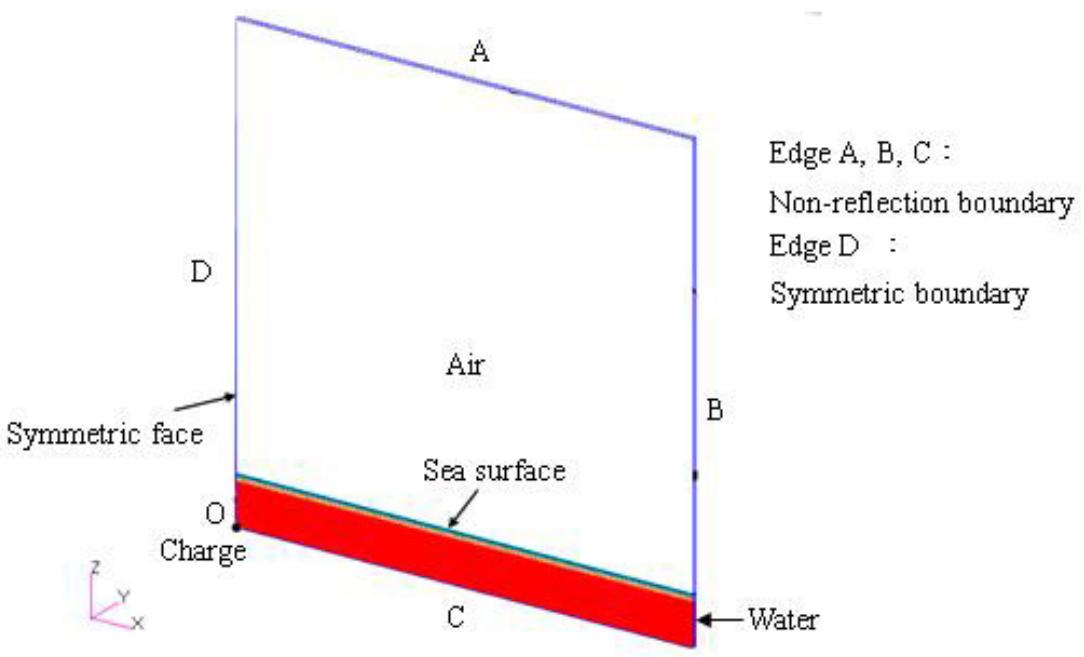

Figure 3: $\quad$ One half of the initial geometry of water problem.

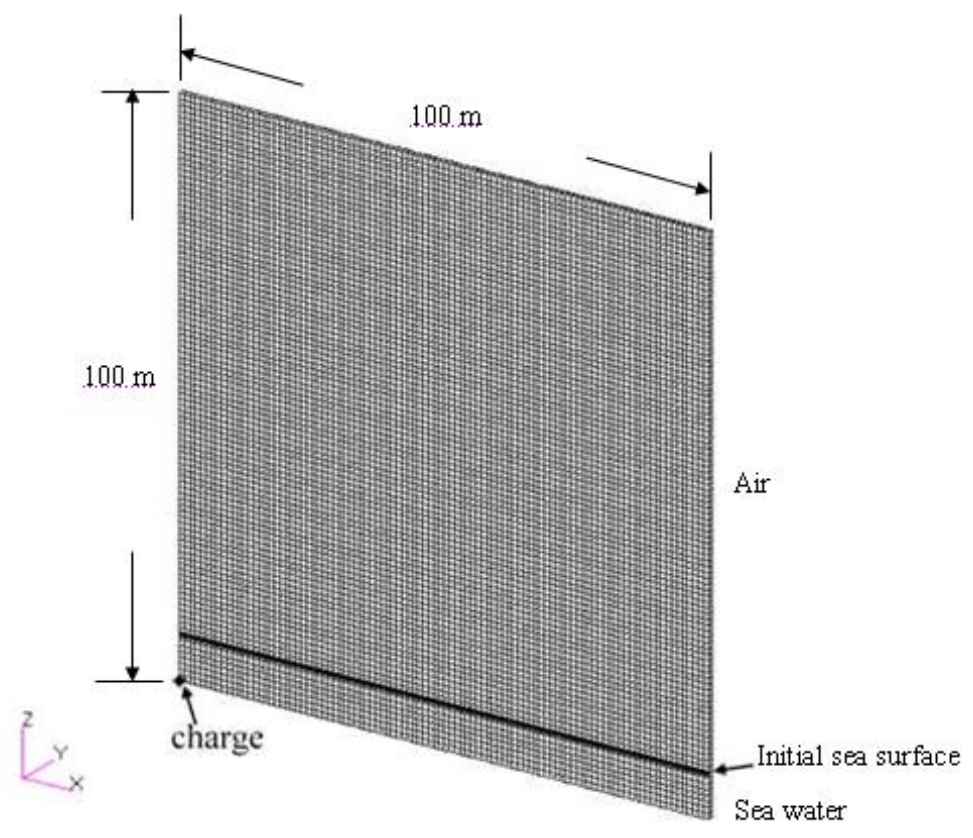

Figure 4: $\quad$ Finite element model for water plume.

By observing Figure 5, the occurrence of the effective phenomenon of the explosion plume was between $1.4 \sim 5.0 \mathrm{~s}$, and the height and thickness of the plume were dense. 
Structures Under Shock and Impact IX 19

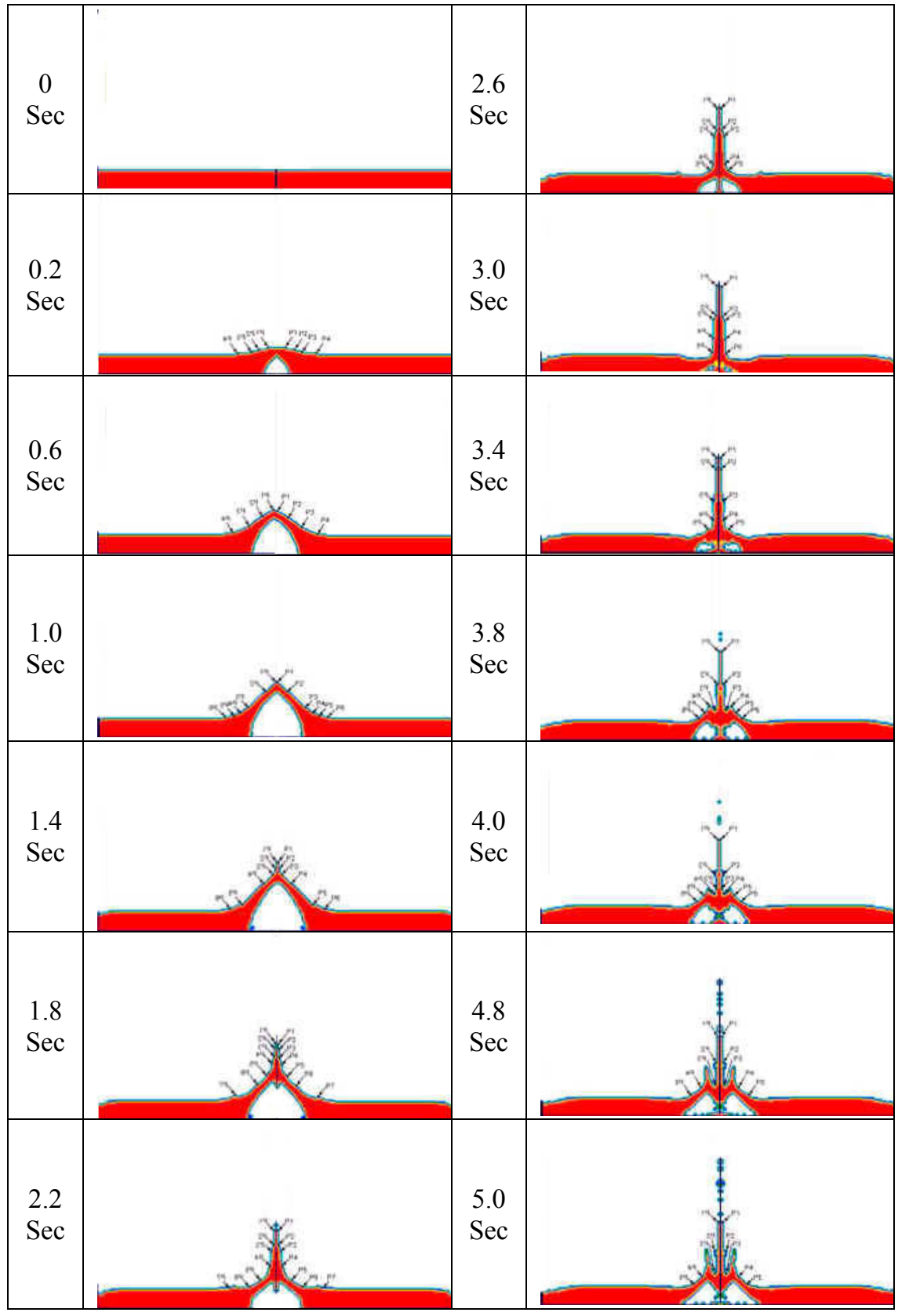

Figure 5: $\quad$ Surface effect of underwater explosion (TNT charge weight in 9.1 $\mathrm{kg}$, explosion depth in $10 \mathrm{~m}$ ). 
In Table 1, we observed the historical change of the effect of water surface (height and thickness of the plume) when the depth of explosion was $10 \mathrm{~m}$. We used MSC.Dytran to compute the biggest height and corresponding thickness of the explosion. At the seven observed points P1, P2, P3, P4, P5, P6, and P7 with Figure 5, the staring moment and the size of the effective plume could be observed; comparing the results of the simulation to the results computed with Michael's semi-empirical method, we found there was still some difference, and the possible reason to the difference was because Michael's method has no clear definition of the biggest height and thickness of the plume.

Table 1: $\quad$ Time history of height and thickness $(10 \mathrm{~m})$.

\begin{tabular}{|c|c|c|c|c|c|c|c|c|c|c|c|c|c|c|c|}
\hline \multicolumn{15}{|c|}{ MSC.Dytran solution } & $\begin{array}{c}\text { Michael } \\
{[5]} \\
\text { empirical }\end{array}$ \\
\hline $\begin{array}{c}\text { Posit } \\
\text { ion }\end{array}$ & $\begin{array}{l}\text { time } \\
(\mathrm{sec}) \\
\end{array}$ & 0.2 & 0.6 & 1.0 & 1.4 & 1.8 & 2.2 & 2.6 & 3.0 & 3.4 & 3.8 & 4.0 & 4.8 & 5.0 & \multirow{15}{*}{$\begin{array}{l}\text { height: } \\
23.4 \mathrm{~m} \\
\text { thickness: } \\
19.4 \mathrm{~m}\end{array}$} \\
\hline \multirow{2}{*}{ P1 } & $\begin{array}{c}\text { height } \\
\text { (m) }\end{array}$ & 4 & 14 & 21 & 26 & 31 & 32 & 36 & 40 & 44 & 38 & 38 & 40 & 36 & \\
\hline & $\begin{array}{l}\text { thick } \\
\text { ness } \\
(\mathrm{m})\end{array}$ & 6 & 2 & 1 & 1 & 1 & 1 & 1 & 1 & 1 & 1 & 1 & 1 & 1 & \\
\hline \multirow{2}{*}{ P2 } & $\begin{array}{l}\text { height } \\
\text { (m) }\end{array}$ & 3 & 11 & 15 & 23 & 28 & 24 & 24 & 23 & 37 & 20 & 18 & 25 & 20 & \\
\hline & $\begin{array}{c}\text { thick } \\
\text { ness } \\
(\mathrm{m})\end{array}$ & 11 & 7 & 7 & 1 & 1 & 1 & 1 & 1 & 1 & 1 & 3 & 1 & 3 & \\
\hline \multirow{2}{*}{ P3 } & $\begin{array}{l}\text { height } \\
\text { (m) }\end{array}$ & 2 & 5 & 7 & 20 & 24 & 20 & 20 & 20 & 19 & 6 & 10 & 12 & 7 & \\
\hline & $\begin{array}{c}\text { thick } \\
\text { ness } \\
(\mathrm{m})\end{array}$ & 15 & 14 & 17 & 3 & 1 & 3 & 3 & 3 & 3 & 3 & 1 & 3 & 3 & \\
\hline \multirow{2}{*}{ P4 } & $\begin{array}{l}\text { height } \\
\text { (m) }\end{array}$ & 1 & 1 & 3 & 14 & 20 & 16 & 5 & 9 & 8 & 7 & 7 & 11 & 6 & \\
\hline & $\begin{array}{l}\text { thick } \\
\text { ness } \\
(\mathrm{m})\end{array}$ & 23 & 24 & 20 & 8 & 3 & 3 & 3 & 4 & 3 & 6 & 3 & 10 & 9 & \\
\hline \multirow{2}{*}{ P5 } & $\begin{array}{l}\text { height } \\
\text { (m) }\end{array}$ & & & 2 & 3 & 14 & 6 & 2 & 2 & 3 & 4 & 6 & 2 & 1 & \\
\hline & $\begin{array}{l}\text { thick } \\
\text { ness } \\
(\mathrm{m})\end{array}$ & & & 24 & 20 & 6 & 9 & 5 & 3 & 6 & 8 & 8 & 16 & 14 & \\
\hline \multirow{2}{*}{ P6 } & $\begin{array}{l}\text { height } \\
\text { (m) }\end{array}$ & & & 1 & 1 & 9 & 1 & & & & 1 & 2 & & & \\
\hline & $\begin{array}{l}\text { thick } \\
\text { ness } \\
(\mathrm{m})\end{array}$ & & & 27 & 27 & 11 & 15 & & & & 12 & 13 & & & \\
\hline \multirow{2}{*}{ P7 } & $\begin{array}{l}\text { height } \\
(\mathrm{m})\end{array}$ & & & & & 3 & 1 & & & & & & & & \\
\hline & $\begin{array}{l}\text { thick } \\
\text { ness } \\
(\mathrm{m})\end{array}$ & & & & & 24 & 26 & & & & & & & & \\
\hline
\end{tabular}


Although the results computed by MSC.Dytran could not correspond to the results computed by Michael's semi-empirical method, we still could do quite realistic simulation of the phenomenon of the effect of water surface (shape of the plume after explosion) resulted from explosion and starting time of the effective plume. In the discussion of the last paragraph, the precision of MSC.Dytran should be used to be the numerical simulation analysis tool to analyze the effect of water surface in underwater explosion.

\section{Conclusion and future work}

In this paper, we used FEM software MSC.Dytran to do the numerical simulation of the effect of water surface after underwater explosion, and we compared the results to the calculation by Michael's semi-empirical method. The important conclusions obtained in this paper were in the following:

(1) FEM software MSC.Dytran could adequately simulate the historical process of the contour of the effective plume, and it could compute the biggest height and thickness of the plume of explosion, and the starting time of the dense plume; although the numerical results done by MSC.Dytran was close to the computational results done by Michael's semi-empirical method, there was still some difference. The possible reason to the difference was that there is no clear definition of the biggest height and width of the plume in the reference presented by Michael. Therefore, we could not find the relative location to do measurement according to the definition of the height and width of the plume defined by Michael. Thus, there was difference between the two results, but MSC.Dytran still could simulate the phenomenon of the effect of water surface resulted from explosion.

(2) While we are using FEM software MSC.Dytran to simulate the effect of water surface, the present personal computer still needed much time to compute to obtain effective data in order to observe the effect of different depth and the weight of explosive to the effect of water surface (starting time, height and thickness of the plume of explosion.)

(3) There are still some problems which can be discussed in the future:

a. Direction of the shock wave: Second pressure wave, refraction and reflection of the shock wave, cavitation resulted from the cut off at water surface etc.

b. Direction of the bubble of explosion: Radius of bubble, pressure of bubble, energy of bubble, transferring path of bubble etc.

c. Safety protection of the barrier: ideal depth of explosion, the effect of barrier resulted from multi-points explosion etc.

We hope the research results in this paper can be referred to the analysis and design of the protection of barrier, the structure and equipments of ship, and the anti-vibration of the device in the underwater buildings.

\section{Acknowledgements}

We would like to thank the National Science Council of the Republic of China for financially supporting this research under contract no. NSC 94-2745-E-212002-URD, and no. 94-2611-E-212-001. 
22 Structures Under Shock and Impact IX

\section{References}

[1] Cole, R.H., "Underwater Explosions," Princeton University Press, Princeton, 1948.

[2] Keil, A.H., "The response of ships to underwater explosions," Annual Meeting of SNAME, New York, 1961.

[3] Smith, P.D. and Hetherington, J.G., "Blast and Ballistic Loading of Structures," Butterworth-Heinemann, 1994.

[4] "MSC.Dytran User's Manual," Mac Neal-Schwendler Corporation, Version 4.7, Los Angeles, CA, 2002.

[5] Swisdak Jr., M.M., "Explosion and properties part II-explosion effects in water," Naval Surface Warfare Center, NSWC/WOL/TR-76-116, 1978. 